\title{
New Regional Editor
}

\author{
Andrei Rotaru
}

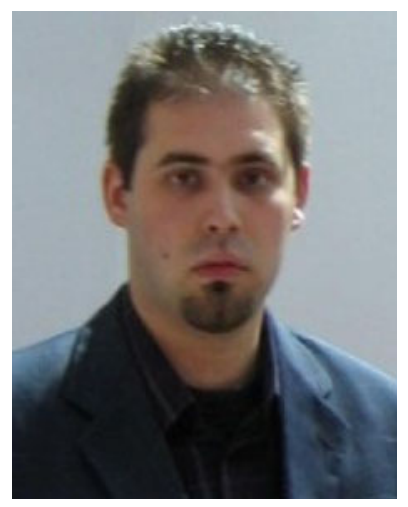

Name: A. Rotaru

Andrei Rotaru was born on the 9th of August 1983 in Craiova, Romania. Since November 2006, he is working at the National Institute for Laser, Plasma and Radiation Physics (INFLPR) Bucharest, Romania, where he currently holds the position of Researcher III (equiv. to Lecturer). Andrei has received his BSc in Chemistry and Physics from the Faculty of Chemistry of the University of Bucharest in 2006, specializing in Physical chemistry. Since 2004, he has carried out research in the field of thermal analysis and kinetics of heterogeneous processes (decomposition of various systems, including liquid crystals and dyes, complex inorganic materials and precursors, biomass and coal). He has also developed a software for performing kinetic computations (TKS-SP) and later on used this knowledge in studying, modelling and processing

A. Rotaru $(\square)$

INFLPR - National Institute for Laser, Plasma and Radiation Physics, Bvd. Atomistilor, nr 409, Măgurele (Ilfov),

Bucharest, Romania

e-mail: andrei.rotaru@inflpr.ro of thin films by laser-assisted techniques (mainly MAPLE). In 2007, Andrei has received an EPSRC grant, followed by a prestigious fellowship of the Roberto Rocca "Educational Program" for his doctoral studies in solid-state chemistry of ceramic materials at the University of $\mathrm{St}$ Andrews, United Kingdom. These more recent interests are related to the fabrication, thermal processing and characterization of novel electroceramic materials with tetragonal tungsten bronze structure. In general, a special interest was directed on modelling relaxation processes in polar dielectric ceramics and investigating the structure-properties relations to induce and control ferroelectricity and ferromagnetism.

In 2011, he was the co-chairman of the 1st Central and East European Conference on Thermal Analysis and Calorimetry (CEEC-TAC1), and in 2008 a member of the scientific committee of the 14th International Congress on Thermal Analysis and Calorimetry (ICTAC14) in Brazil; he is a member of the International Confederation for Thermal Analysis and Calorimetry (ICTAC), Commission for Thermal Analysis and Calorimetry of the Romanian Academy (CATCAR), Kinetics committee at ICTAC, International Society for Optics and Photonics (SPIE), and president of the Central and Eastern European Committee for Thermal Analysis and Calorimetry (CEEC-TAC). Currently, he acts as an editor for thermal analysis at the Global Journal of Analytical Chemistry and as a reviewer for several journals: The Journal of Physical Chemistry, Journal of Thermal Analysis and Calorimetry, Thermochimica Acta, Journal of Applied Polymer Science, Dyes \& Pigments, Chemical Industry \& Chemical Engineering Quarterly, etc.

Andrei has been an invited lecturer at several universities and institutes from Lithuania, Estonia, Slovakia, Czech Republic, Poland, and is directly involved and interested in 
developing cooperation between researchers from central and eastern European countries. He has published 25 scientific papers and presented numerous studies at conferences. His articless were cited until now for 85 times; he has a Hirsch index of 7 and an individual ISI impact factor of $\sim 10$.

\section{Relevant publications}

1. Origin and stability of dipolar response in a family of tetragonal tungsten bronze relaxors; Andrei Rotaru, Donna C. Arnold, Aziz Daoud-Aladine, Finlay D. Morrison; Physical Review B, 83, 18, 184302, 2011.

2. Matrix assisted pulsed laser evaporation of zinc benzoate for $\mathrm{ZnO}$ thin films and non-isothermal decomposition kinetics; Andrei Rotaru, Catalin Constantinescu, Anca Mândruleanu, Petre Rotaru, Antoniu Moldovan, Katarina Győryová, Maria Dinescu, Vladimir Balek; Thermochimica Acta, 498, 1-2, 81-91, 2010.

3. DSC study on hyaluronan hydration and dehydration; Jiri Kucerik, Alena Prusova, Andrei Rotaru, Karol Flimel, Jiri Janacek, Pelegrino Conte; Thermochimica Acta, 523, 1-2, 245-249, 2011.

4. Computational thermal and kinetic analysis. Complete standard procedure to evaluate the kinetic triplet form non-isothermal data; Andrei Rotaru, Mihai Goşa; Journal of Thermal Analysis and Calorimetry, 97, 2, 421-426, 2009.

5. Thermal decomposition kinetics of some aromatic azomonoethers; Part I.Decomposition of 4-[(4-chlorobenzyl)oxy]-4'-nitro-azobenzene; Andrei Rotaru, Anca Moanţă, Ion Sălăgeanu, Petru Budrugeac, Eugen Segal; Journal of Thermal Analysis and Calorimetry, 87, 2, 345-355, 2007.

\section{Most cited papers}

1. Heteroleptic $\mathrm{Cd}(\mathrm{II})$ complex, potential precursor for semiconducting CdS layers. Thermal stability and nonisothermal decomposition; Anna Kropidłowska, Andrei Rotaru, Michal Strankowski, Barbara Becker, Eugen Segal; Journal of Thermal Analysis and Calorimetry, 91, 3, 903-909, 2008 (13 Citations)

2. Thermal decomposition kinetics of some aromatic azomonoethers; Part I.Decomposition of 4-[(4-chlorobenzyl)oxy]-4'-nitro-azobenzene; Andrei Rotaru, Anca Moanţă, Ion Sălăgeanu, Petru Budrugeac, Eugen Segal; Journal of Thermal Analysis and Calorimetry, 87, 2, 345-355, 2007 (10 Citations)

3. Thermal decomposition kinetics of some aromatic azomonoethers. Part III. Non-isothermal study of 4-[(4-chlorobenzyl)oxy]-4'-chloro-azobenzene in dynamic air atmosphere; Andrei Rotaru, Anca Moanţă, Petre Rotaru, Eugen Segal; Journal of Thermal Analysis and Calorimetry, 95, 1, 161-166, 2009 (9 Citations)

4. CdS thin films obtained by thermal treatment of cadmium (II) complex precursor deposited by MAPLE technique; Andrei Rotaru, Anna Mietlarek-Kropidłowska, Catalin Constantinescu, Nicu Scărişoreanu, Marius Dumitru, Michal Strankowski, Petre Rotaru, Valentin Ion, Cristina Vasiliu, Barbara Becker, Maria Dinescu; Applied Surface Science, 255, 15, 6786-6789, 2009 (7 Citations)

5. Thermal stability of some new complexes bearing ligands with polymerisable groups; Mihaela Badea, Rodica Olar, Dana Marinescu, Eugen Segal, Andrei Rotaru; Journal of Thermal Analysis and Calorimetry, 88, 2, 317-321, 2007 (7 Citations) 